\title{
Lycopene enhances the anti-proliferative and pro-apoptotic effects of capsaicin in prostate cancer in vitro
}

\author{
Natalie A Venier ${ }^{1}$, Alexandra J Colquhoun¹, Neil E Fleshner², Laurence H Klotz ${ }^{1}$ and Vasundara Venkateswaran ${ }^{1 *}$ \\ Correspondence: vasundara.venkateswaran@sunnybrook.ca \\ 'Division of Urology, Department of Surgery, Sunnybrook Health Sciences Centre, Toronto, ON, Canada. \\ ${ }^{2}$ Division of Urology, Department of Surgery, Princess Margaret Hospital, Toronto, ON, Canada.
}

\begin{abstract}
Background: Increasing evidence suggests dietary factors influence the development and progression of prostate cancer (PCa). The chemopreventive properties of lycopene, the antioxidant found in tomatoes, have been extensively studied for $\mathrm{PCa}$; however, the effect of lycopene, as a single agent, remains unclear. Studies that are more promising, involve using lycopene in combination with other dietary agents. Capsaicin, the active compound in chilli peppers, is reported to exert potent anti-cancer effects in both in vitro and in vivo PCa models. We have investigated whether lycopene enhances the anti-proliferative and apoptotic effects of capsaicin in vitro.
\end{abstract}

Methods: Using the MTS Cell Proliferation Assay we assessed the anti-proliferative effect of capsaicin alone, or in combination with lycopene in human PCa cell lines (LNCaP, PC3, PC3-AR2, DU145) and prostate stromal cells. Flow cytometry and Western Blotting techniques were used to assess potential mechanisms of interaction.

Results: Capsaicin exhibited anti-proliferative and pro-apoptotic effects, which were significantly enhanced with the addition of lycopene to PCa cells. The greatest effects were observed in androgen-sensitive cell lines. Detailed mechanistic studies revealed this combination may be interrupting the androgen-signaling pathways; independent of TRP-V1 signaling. Cell cycle analysis revealed that capsaicin and lycopene induce a cell cycle arrest, corresponding to alterations in tumor-suppressor proteins. Treating LNCaP cells with capsaicin and lycopene also altered proteins involved the apoptosis signaling pathway including, cleaved PARP, Caspase-3 and Bax/Bcl-xL expression.

Conclusions: Our results suggest that lycopene enhances the anti-cancer properties of capsaicin. Understanding micronutrient interactions may help improve current chemoprevention strategies.

Keywords: prostate neoplasm, capsaicin, lycopene, anti-proliferation, apoptosis, chemoprevention

\section{Introduction}

Prostate cancer remains the most commonly diagnosed cancer in men living in the Western world [1]. There is increasing evidence that dietary factors play a role in the development and progression of prostate cancer. It is estimated that at least $30 \%$ of all prostate cancer patients use complementary and alternative medicine, which includes the consumption of micronutrient supplements [2]. Many dietary agents have been studied for the protective effects on prostate cancer [3,4]. Although a clear understanding of how these micronutrients interact with each other is largely unknown, many micronutrient supplements often contain a variety of dietary agents. Hence, studies examining the interaction of these dietary agents are essential for more effective chemopreventive regimens.

Lycopene, a potent antioxidant and carotenoid found in high concentrations in tomatoes, is one of the most extensively studied micronutrients for the chemoprevention of prostate cancer $[5,6]$. Despite numerous studies, the protective effect of lycopene, as a single agent, on prostate cancer remains unclear [7]. In 2004, Hantz et al. [8] reported that lycopene induced apoptosis in androgen-sensitive prostate cancer cells, mediated through the disruption of the mitochondrial membrane and the generation of reactive oxygen species (ROS). Subsequent studies however have been unable to successfully replicate these findings [7]. More recent studies suggest the protective effects of lycopene to be most apparent in combination studies. Recently, our group has found that combining lycopene with vitamin $E$ and selenium resulted in significant inhibition of the growth and development of prostate tumours in the Lady transgenic mouse model compared to vitamin $E$ and selenium alone, demonstrating that lycopene was necessary for effective combination regimens [9]. Lycopene has also been found to enhance the effect of other therapies [10].

Capsaicin has recently emerged as a potent anti-cancer agent, exhibiting anti-proliferative and pro-apoptotic 
properties in several different prostate cancer model systems [11]. It is widely consumed as a food additive throughout the world, particularly in areas with a low incidence of prostate cancer, such as, South East Asia. The use of capsaicin in vitro has been reported to induce apoptosis through the generation of ROS, dissipation of the mitochondrial inner transmembrane potential and downstream activation of the caspase-3 cascade [12-16]. It also demonstrates efficacy in vivo by suppressing the growth of prostatic tumour xenografts in nude mice [13]. A recent case study reported by Jankovic et al., [17] describes a 66-year-old patient with prostate cancer who experienced significant improvement in his PSA levels upon daily consumption of capsaicin. Cessation of the capsaicin was followed by a sharp increase in his PSA levels (challenge/re-challenge effect) and PSA trends suggesting a dose-response relationship [17].

In our present study, we have investigated for the first time, whether lycopene enhances the effect of capsaicin using an in vitro prostate cancer model. Through proliferation studies, flow cytometry and protein analysis techniques, we have found that the anti- proliferative and pro-apoptotic effects of capsaicin are greater when it is combined with lycopene. Our in vitro analysis suggests that these anti-proliferative effects may be mediated through androgen-signalling pathways, independent of the capsaicin receptor, TRP-V1.

\section{Materials and methods Cell culture}

Three human prostate cancer cell lines (DU145, LNCaP and $\mathrm{PC} 3$ ) and the prostate stromal cell line ( $\mathrm{PrSC}$ ) were obtained from the American Type Culture Collection (Rockville, Maryland, USA). PC3-AR2 cells (generous gift from Dr Ted Brown, Mount Sinai Hospital, Toronto, ON, Canada) are PC3 cells transfected with a full length functional androgen receptor (AR). Cells were cultured at $37^{\circ} \mathrm{C}$ in a $5 \% \mathrm{CO}_{2}$ incubator in the following media; LNCaP cells, RPMI 1640 medium (Invitrogen, Burlington, ON, Canada) supplemented with $10 \%$ fetal bovine serum (FBS; Gibco, Grand Island, $\mathrm{NY}, \mathrm{USA}), 0.3 \mathrm{mg} / \mathrm{ml} \mathrm{l}$-glutamine and $100 \mathrm{IU} / \mathrm{ml}$ penicillin and $100 \mu \mathrm{g} / \mathrm{ml}$ streptomycin (Invitrogen, Burlington, ON Canada); PC3 and DU145 cells, Dulbecco's minimal essential medium/F12 (Invitrogen, Burlington, ON, Canada) with $10 \%$ FBS supplemented with $0.3 \mathrm{mg} / \mathrm{ml} \mathrm{l-glutamine}$ and $100 \mathrm{IU} / \mathrm{ml}$ penicillin and $100 \mu \mathrm{g} / \mathrm{ml}$ streptomycin; PC3AR2 cells, RPMI 1640 medium supplemented with 5\% FBS, $0.3 \mathrm{mg} / \mathrm{ml} \mathrm{l}$-glutamine, $100 \mathrm{IU} / \mathrm{ml}$ penicillin and $100 \mu \mathrm{g} / \mathrm{ml}$ streptomycin, Fungizone $(250 \mu \mathrm{g} / \mathrm{ml}$ amphotericin B and $250 \mu \mathrm{g} / \mathrm{ml}$ deoxycholate, Invitrogen, Burlington, ON, Canada) and $100 \mu \mathrm{g} / \mathrm{ml}$ hygromycin B (Invitrogen, Burlington, ON, Canada). PrSC were maintained in RPMI 1640 media as per LNCaP cells. All cells were grown under sterile conditions at $37^{\circ} \mathrm{C}$ with $5 \% \mathrm{CO}_{2}$.

\section{Chemicals}

Capsaicin (trans-8-methyl-N-vanillyl-6-nonenamide) was obtained from Tocris (Bristol, UK) and Capsazepine (CZP) was obtained from Santa Cruz Biotechnology (CA, USA). Both capsaicin and CZP were dissolved in dimethyl sulfoxide (DMSO, Sigma, USA) to create a stock concentration of $0.1 \mathrm{M}$ and stored at $-20^{\circ} \mathrm{C}$. Lycopene was obtained from Sigma (USA) and was dissolved in tetrahydrofuran (THF) to create a $0.01 \mathrm{M}$ stock solution. Lycopene was stored in a dark area at $-80^{\circ} \mathrm{C}$. Stock solutions of capsaicin $(10-200 \mu \mathrm{M})$, capsazepine $(10 \mu \mathrm{M})$ and lycopene $(10 \mu \mathrm{M})$ were diluted in appropriate medium and prepared fresh daily prior for treatment. All compounds were prepared and stored with minimal exposure to light to avoid oxidation. All other chemicals were purchased from Sigma unless otherwise specified.

\section{Cell proliferation assay}

Proliferation was assessed using the CyQuant MTS cell proliferation assay (Molecular Probes, OR, USA). Cells were plated in 96-well micro-titre plates, at a density of 500 (PrSC) or 5000 (LNCaP, PC3, PC3AR2, DU145) cells per well. Cells were left to adhere for 24 hours and then treated accordingly. Initial standardization was carried out using a range of doses of capsaicin from $0 \mu \mathrm{M}-200 \mu \mathrm{M}$, or lycopene $0 \mu \mathrm{M}-100 \mu \mathrm{M}$ (lycopene data not shown). Combination studies were carried out using $100 \mu \mathrm{M}$ concentration of capsaicin, and $10 \mu \mathrm{M}$ of lycopene. For antagonist studies using CZP and/or capsaicin, cells were treated with a range of doses of capsaicin (0-100 $\mu \mathrm{M})$ or with or without CZP $(10 \mu \mathrm{M})$; treatments were applied at the same time. All experiments were carried out in triplicates and repeated a minimum of three times. Control wells were treated with vehicle alone (DMSO - $0.02 \%$ and THF - 0.01\%). Cells were then incubated for 24 hours post treatment. At the end of the treatment period, $20 \mu \mathrm{L}$ of tetrazolium dye was added to each well and cells incubates for 2 hours. Absorbance was measured using a $96-$ well plate reader at $490 \mathrm{~nm}$.

\section{Western blot analyses}

$\mathrm{LNCaP}, \mathrm{PC} 3$ or PC3AR2 cells were plated in petri dishes at a density of $1 \times 10^{6}$ cells per plate. After 24 hours, adherent cells were incubated with lycopene $(10 \mu \mathrm{M})$ and/or capsaicin $(100 \mu \mathrm{M})$. Control wells were treated with vehicle alone (DMSO $-0.02 \%$ and THF $-0.01 \%$ ). After 24 hours cells were lysed (NP40 lysis buffer with inhibitors (leupeptin/pepstatin, aprotinin and phenylmethanesulfonylflouride), sodium dodecyl sulfate (SDS), deoxychalate and ethylenediaminetetraacetic acid). In our time-point analysis, LNCaP cells were lysed at $3,6,12,24$, and 48 hours. Protein was quantified using the Bradford protein assay technique prior to loading into $12 \%$ SDS gels for electrophoresis. Following protein transfer, membranes were probed to assess; i) receptor expression levels (AR, Santa Cruz), ii) prostate specific antigen (PSA, Santa Cruz), iii) markers of apoptosis (BAX, $\mathrm{Bcl}-2$ and caspase-3 from Cell Signaling), proliferation 
(PCNA, Santa Cruz) and cell cycle regulatory molecules markers (p21 and p27 from Cell Signaling and p53 from Santa Cruz ). Image quantification software (ImageJ, US National Institute of Health, Bethesda, MD, USA) was used to semi- quantitatively determine protein expression levels, relative to $\beta$-actin [23].

\section{Flow cytometry}

Cell cycle arrest pattern and alterations in the percentage of cells in the $S$ phase enumeration were determined in LNCaP cells by flow cytometry on cells labelled with antibromodeoxyuridine (BrdU) fluorescein isothiocyanate (FITC) and counterstained with propidium iodide (PI). Asynchronously growing cells ( $5 \times 10^{5}$ cells/plate) were plated in $10 \mathrm{~cm}$ petri dishes and left to adhere for 24 hours, subsequently cells were treated for 24 hours with lycopene $(10 \mu \mathrm{M})$ and/or capsaicin $(0.1 \mu \mathrm{M}-100 \mu \mathrm{M})$. Control plates were treated with vehicle alone (DMSO $-0.02 \%$ and THF $-0.01 \%$ ). ICells were pulse labeled with BrdU for 2 hours, washed with PBS (Invitrogen), trypsinised, fixed in ice cold $70 \%$ ethanol and stored at $-20^{\circ} \mathrm{C}$ until further analysis. Cells were washed in buffer PBSS, Invitrogen, (Burlington, ON, Canada) and $0.5 \%$ Tween-20) and treated with $2 \mathrm{~N} \mathrm{HCl}$ for 20 mins to expose labeled DNA and neutralized with $\mathrm{Na}_{2} \mathrm{~B}_{4} \mathrm{O}_{7}(\mathrm{pH}$ 8.5) for 2 minutes. Cells were incubated for $1 \mathrm{hr}$ on ice with anti-BrdU conjugated FITC (DAKO, Burlington, ON, Canada). Cells were washed, centrifuged, and resuspended in 10 $\mu \mathrm{g} /$ $\mathrm{ml} \mathrm{PI}$, and allowed to incubate for 30 min on ice. Samples were filtered through a nylon mesh and cell cycle analysis performed on the FACSCalibur flow cytometer using the Cell Quest Pro software package (Becton Dickinson, San Jose, CA, USA).

\section{Statistical analysis}

Data are presented as the mean \pm S.D. of three experiments or more. Statistical comparisons among groups were made with a Student's t test or the one-way analysis of variance (ANOVA) test. Results were considered significant at the $5 \%$ critical level $(p<0.05)$.

\section{Results}

\section{Differential growth inhibitory effect of capsaicin on} prostate cell lines

Using the MTS Cell Proliferation Assay we assessed the effect of capsaicin on the growth of several prostate cancer cell lines and a non-malignant prostate stromal cell line (Figure 1a). Results reveal that treatment of capsaicin at a concentration of $0-200 \mu \mathrm{M}$ inhibited the growth of $\mathrm{LNCaP}$, PC3 and PC3AR2 cells in a dose-dependent manner. The androgen-insensitive cell line, DU145, was unaffected by capsaicin at any of the concentrations. The non-malignant prostate stromal cells (PRSC) had a reduction in proliferation when treated with capsaicin at $100 \mu \mathrm{M}$; however, this inhibition was not dose-dependent. Lycopene (0-50 $\mu \mathrm{M})$ did not reduce the proliferation of any cell line, except for
LNCaP cells (data not shown). Based on these findings, a 10 $\mu \mathrm{M}$ concentration of lycopene, (minimal dose at which we found an affect), and $100 \mu \mathrm{M}$ concentrations of capsaicin, were used for subsequent combination studies.

\section{Treating cells with a combination of capsaicin and lycopene reduces cell proliferation}

To determine whether the anti-proliferative effect of capsaicin could be enhanced by lycopene, we treated cells with capsaicin $(100 \mu \mathrm{M})$ along with a low-dose lycopene $(10 \mu \mathrm{M})$ (Figure 1b-e). Lycopene used in monotherapy significantly reduced cell growth only in LNCaP cells $(p<0.05)$. Interestingly, treating cells with a combination of capsaicin and lycopene significantly reduced the proliferation of all prostate cancer cell lines, (LNCaP, PC3, PC3AR2 $(p<0.001$; DU-145, $p<0.05$ ). The combination of capsaicin and lycopene reduced the proliferation of PRSC, no significance was observed with either agent alone.

\section{Capsaicin and lycopene in combination alters the} percentage of cells in the S-phase of the cell cycle

To determine the minimal concentration of capsaicin and lycopene that resulted in a significant reduction in the percentage of cells in the S-phase of the cell cycle, flow cytometric analysis was performed on $\mathrm{LNCaP}$ cells with a low dose of lycopene $(10 \mu \mathrm{M})$ and increasing concentrations of capsaicin (0-100 $\mu \mathrm{M})$. Lycopene treatment alone was not effective at altering the percentage of cells in the S-phase. Low concentrations of capsaicin $(0-10 \mu \mathrm{M})$ did not reduce the percentage of cells in the S-phase of the cell cycle. At a concentration of $50 \mu \mathrm{M}$, the combination of capsaicin and lycopene was effective at reducing the percentage of cells from the S-phase at a $10 \mu \mathrm{M}$ concentration of lycopene, greater than either agent alone. Similar effects were seen at $100 \mu \mathrm{M}$ concentration of capsaicin. Concentrations of capsaicin greater than $100 \mu \mathrm{M}$ resulted in a significant reduction in the reduction $(p<0.05)$ in the percentage of cells in the S-phase compared to control. At these concentrations, there were no significant differences between the capsaicin alone or in combination with lycopene. At these concentrations the combination of capsaicin and lycopene reduced percentage of cells in the S-phase greater than either agent alone (Figure 2).

Treatment with capsaicin and lycopene reduce Androgen Receptor (AR) and Prostate Specific Antigen (PSA) expression in LNCaP Cells

To better understand the effect of capsaicin and/or lycopene on androgen-sensitive cells, we examined the expression levels of AR and PSA. Capsaicin treatment alone caused a marked reduction in AR expression in LNCaP cells. Treatment of LNCaP cells with lycopene monotherapy did not affect AR or PSA expression. Interestingly, treating cells with a combination of capsaicin and lycopene resulted in a reduced expression of PSA and AR, greater than either individual 


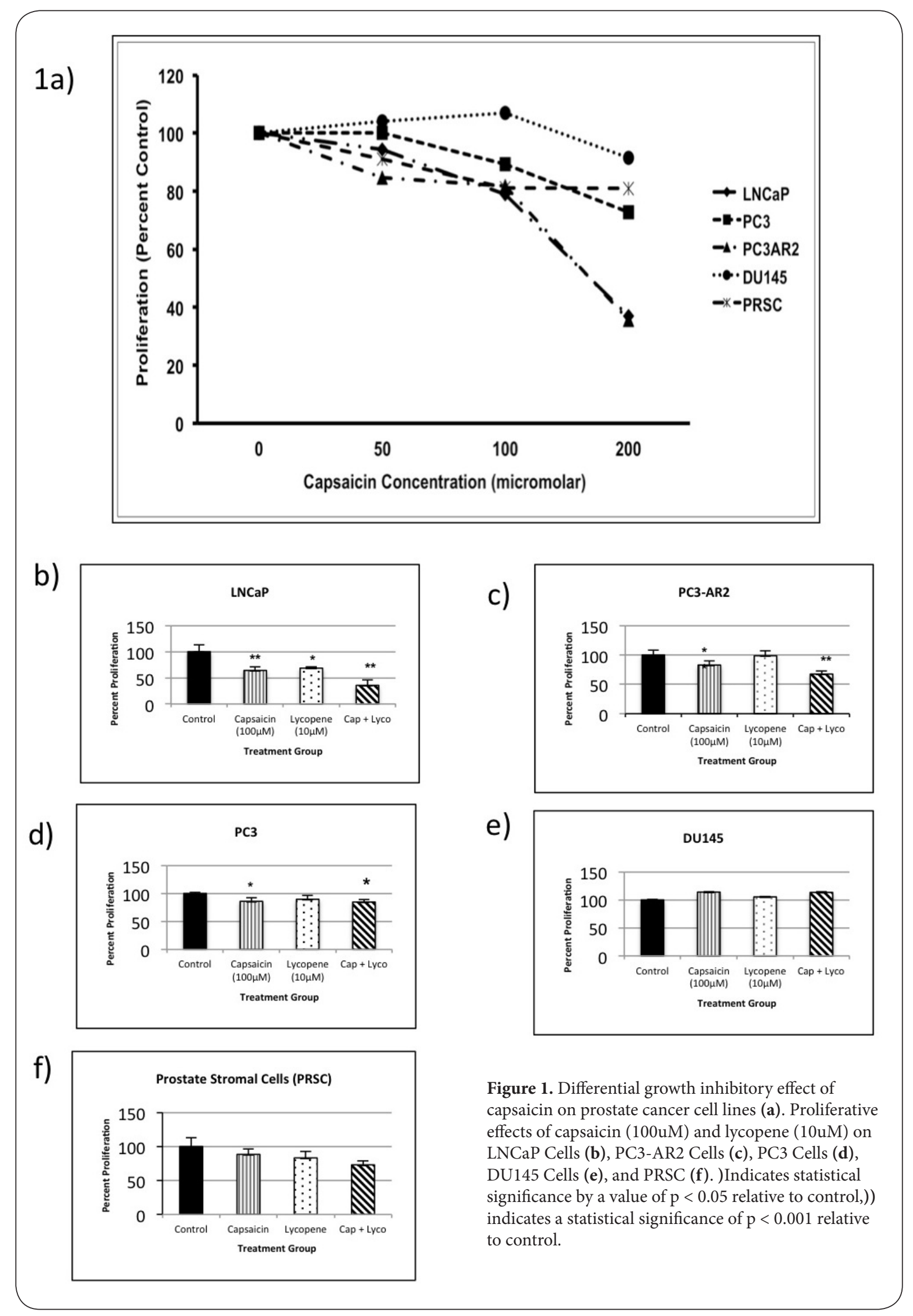




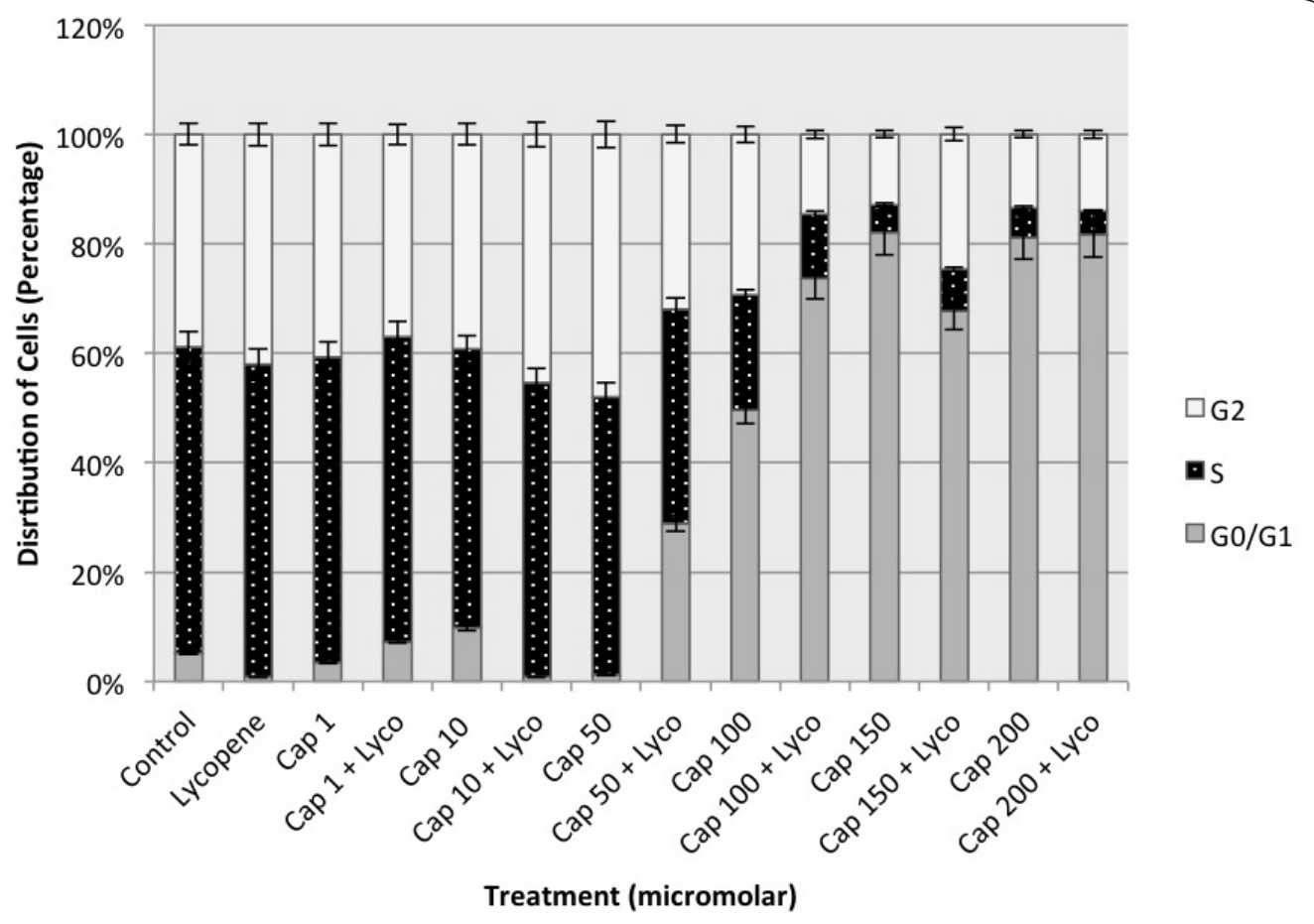

Figure 2: Alterations in the cell cycle distribution (G1, S, G2/M) in LNCaP cells treated with capsaicin and lycopene. Cells treated with capsaicin demonstrated a dose-dependent reduction in the percentage of cells in the S-phase.

treatment (Figure 3).

\section{A combination of capsaicin and lycopene promote apoptosis in androgen-sensitive cells}

Based on our cell cycle profiles obtained by flow cytometry, we examined proteins implicated in the apoptotic pathway using Western Blot analysis. Lycopene treatment alone, did not significantly alter the apoptotic pathway. We found a time-dependent increase in the expression of cleaved PARP (Poly ADP ribose polymerase) to a greater extent than either agent alone, maximal at 24 hours (Figure $4 a$ ). At the 24 hour time point, we found an increase in the $B A X: B C L-x L$ ratio and reduction in total Caspase 3 in androgen-sensitive cell lines, LNCaP and PC3AR2; this effect was not found in the androgen-resistant, $P C 3$, cell line. (Figure 4b). These findings suggest that lycopene is enhancing the pro-apoptotic effect of capsaicin.

The TRP-V1 antagonist, capsazepine (CZP), does not inhibit the anti-proliferative effects of capsaicin Using the TRP-V1 antagonist, CZP, we assessed whether the anti-proliferative effects of capsaicin could be reversed. We observed no significant changes in proliferation with CZP and capsaicin, indicating that capsaicin's effects were not mediated through the TRP-V1 receptor (data not shown), suggesting an alternative mechanism for proliferation.

\section{Discussion}

In our study, we report for the first time that lycopene, a micronutrient well studied for prostate cancer prevention, enhances the anti-proliferative and pro-apoptotic effects of capsaicin in prostate cancer cells. Previous in vivo reports published by our group, have shown that lycopene in combination with antioxidants can significantly reduce the incidence and progression of prostate tumors in the Lady transgenic mouse model [9]. Lycopene has also been described as a necessary component of combinatorial studies. Recently, Tang et al., have reported the enhancing effect of lycopene in combination with other chemotherapeutic agents, including docetaxel [10].

The lack of consensus in the literature about the antiproliferative effects of lycopene as a single agent has yet to be resolved. Few studies report that lycopene reduces cell proliferation in vitro; however, several others have been unable to successfully translate these findings in related preclinical/clinical model systems $[5,7]$. In our present study, we have demonstrated that lycopene, as a single agent, does not have the potential to reduce the proliferation in several prostate cancer cell lines, except in the androgensensitive, LNCaP cells. This differential effect of lycopene on androgen-sensitive cell lines has been previously described [18]. Cell cycle distribution analysis on LNCaP cells revealed that treatment with lycopene resulted in a 


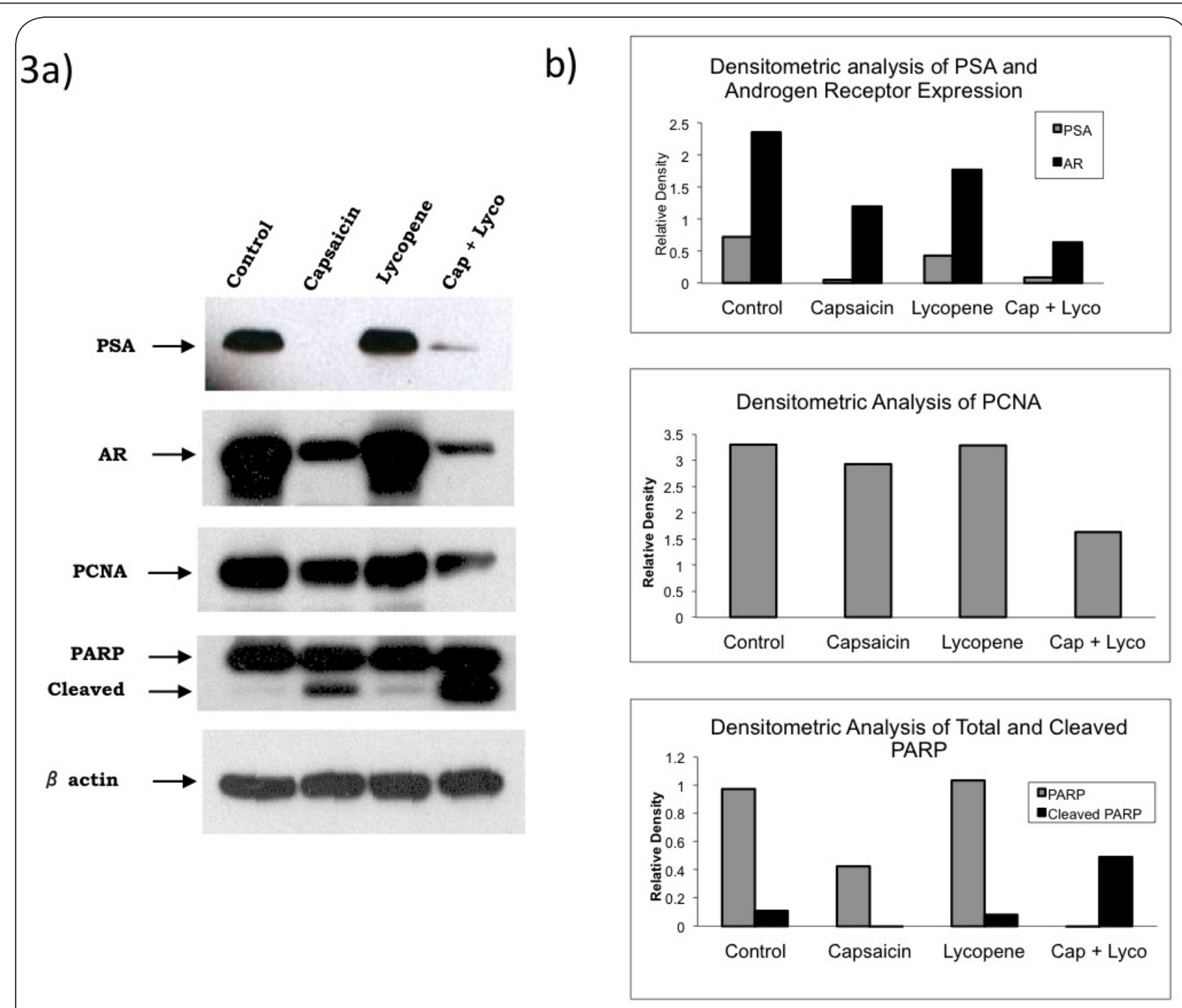

Figure 3. Western Blot analyses demonstrates the changes in the expression of a) Prostate Specific Antigen (PSA), Androgen Receptor (AR), Proliferating Cell Nuclear Antigen (PCNA), and apoptotic indicator, Cleaved PARP in LNCaP cells treated with capsaicin $(100 \mu \mathrm{M})$ and/or lycopene $(10 \mu \mathrm{M})$; b) Corresponding densitometric analysis.

non-significant reduction of the percentage of cells in the S-phase. However, when combined with capsaicin, this reduction in the percentage of cells in the S-phase was significantly greater than either monotherapy, indicating that cell-cycle arrest induced by lycopene may augment the anti-proliferative effects induced by capsaicin. Alterations in protein expression, particularly a reduction in PCNA and the up-regulation of the tumour suppressor proteins, $\mathrm{p} 21^{\mathrm{cip} 1}$ and $227^{k i p 1}$ support these findings. Suggesting that the inhibition of the cell cycle is one possible way in which lycopene is making cell more susceptible to the inhibitory effects of capsaicin. Reduction of p21 ${ }^{c i p 1}$ and p $27^{k i p 1}$, by the combination of capsaicin and lycopene suggest that alternative anti-proliferative mechanisms and/or apoptotic mechanisms may play a role in understanding how these micronutrients are acting in combination [19].
Androgen signalling plays a key role in prostate cancer growth and development [20]. Some of the most promising chemopreventive agents for prostate cancer include the 5-alpha reductase inhibitors, which block the conversion of testosterone to the more potent dihydrotestosterone (DHT), thereby inhibiting prostate cancer growth [21]. The inhibition or activation of the AR causes alterations in the growth and proliferation of prostate cancer cells [22]. Our findings suggest that capsaicin and lycopene may reduce proliferation through the inhibition of androgen signalling. The effect of capsaicin on androgen signalling has been previously reported $[12,13]$. Studies carried out by Mori et al. [12], have found that capsaicin can cause a significant down-regulation in the expression of androgen-receptor and PSA in androgen-sensitive cells. In our study, we have successfully replicated these findings and demonstrated that 
4a)

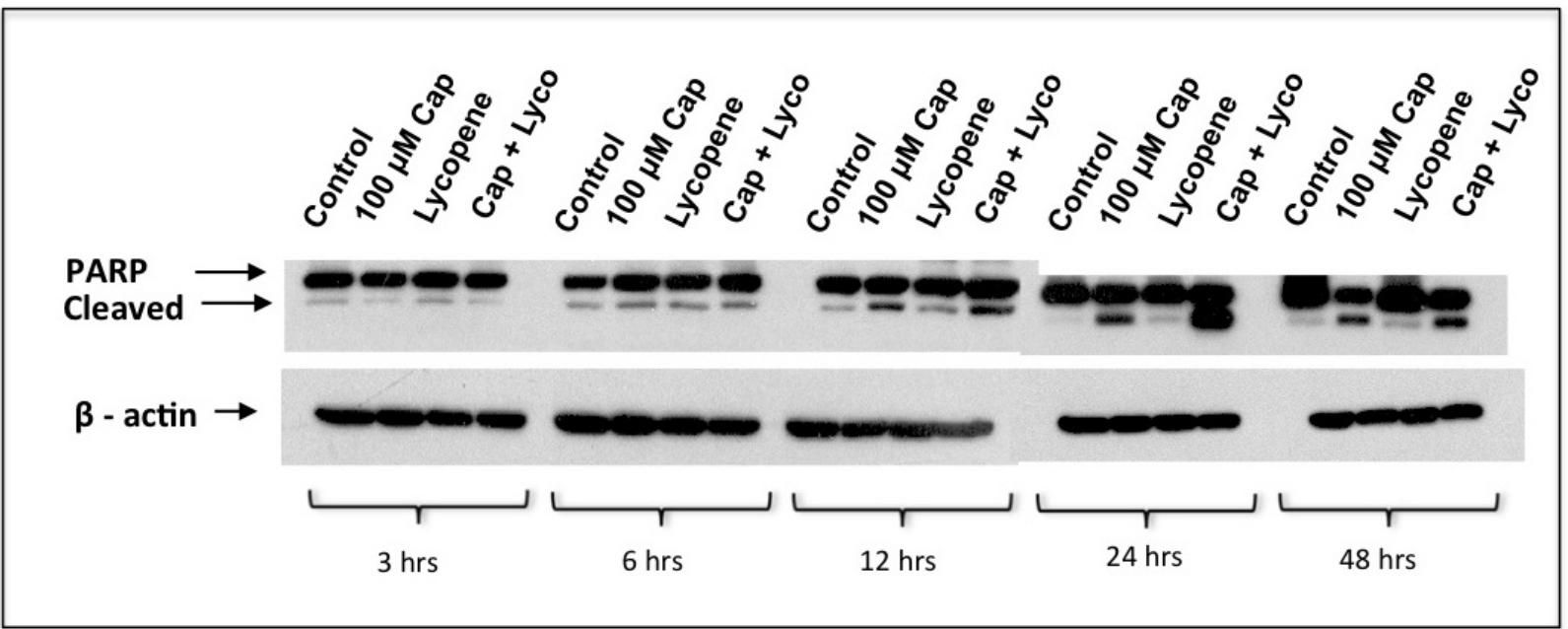

b)

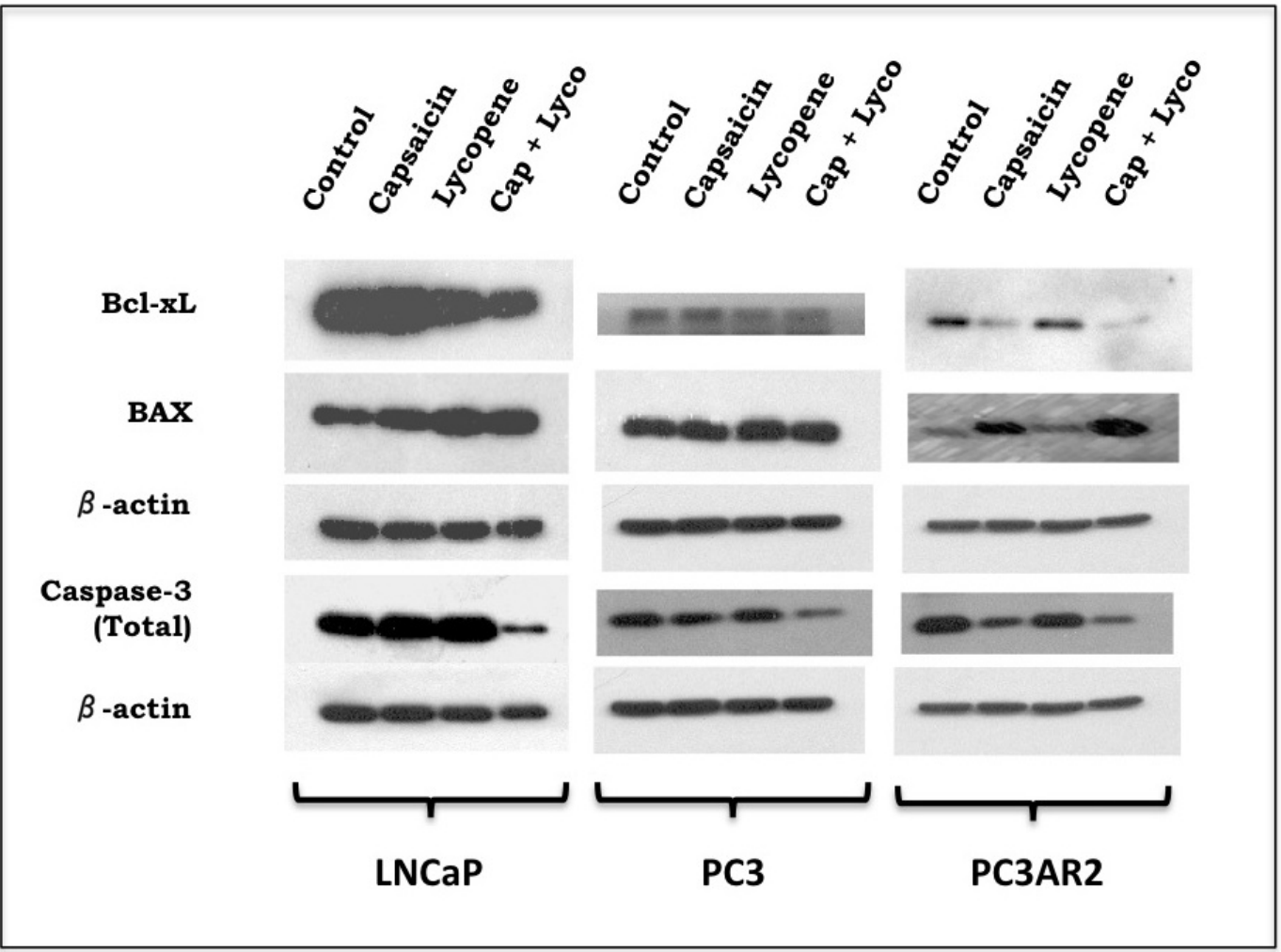

Figure 4. Western blot analysis reveals that a combination of capsaicin and lycopene a) induces the expression of cleaved PARP, in a time-dependent manner; b) At 24 hours, alters the Bax:Bcl-xL ratio and reduces total caspase-3 in LNCaP and PC3AR2 cells; no changes observed in PC3 cells. 
androgen-sensitive cell lines have an enhanced sensitivity to the anti-cancer effects of capsaicin in combination with lycopene.

We have compared both androgen-sensitive and insensitive cell lines and determined androgen-sensitive cells are most responsive to the anti-proliferative effects of capsaicin and lycopene. In particular, we have compared the PC3 and PC3 AR2 (PC3 AR2 cells are PC3 cells transfected with a full length $A R$ ) cell lines. We demonstrated that the incorporation of a functional AR to PC 3 cells causes cells to have an increased sensitivity to the anti-proliferative effects of capsaicin and lycopene, comparable to the LNCaP cell line, suggesting that a functional AR is an important determinant for inhibition of prostate cancer cell proliferation through the use of capsaicin and/or lycopene. Secondly, we have demonstrated that capsaicin and lycopene can reduce protein expression levels of AR and PSA. We have observed that treatment with a combination of lycopene and capsaicin reduces the expression of $A R$, this effect being significantly greater than either agent alone, indicating that these compounds may be acting through the androgen-signalling pathway. It is likely that the inhibition of PSA is mediated at least partly through the down-regulation of the AR. Whether the down- regulation of PSA is enhanced by lycopene, is not clear from our studies. Although the combination of capsaicin and lycopene enhance the down-regulation of $A R$, does not further reduce PSA, suggesting that PSA may be mediated through an androgen- independent manner.

The role of the transient receptor vanilloid-1 receptor (TRP-V1), commonly referred to as the capsaicin receptor, in prostate cancer chemoprevention has not been clearly elucidated. In our studies, we have found that the capsaicin antagonist, capsazepine, does not reverse the antiproliferative effects of capsaicin. Furthermore, there is not significant difference in the expression of this receptor, suggesting that the effects of capsaicin are not TRP-V1 dependent.

Accumulating data clearly indicate that the induction of apoptosis is an important event for the chemoprevention of prostate cancer by naturally occurring dietary agents [23]. Capsaicin has been reported to induce apoptosis through a number of pathways in prostate cancer cells [12-16]. In our present studies, we have found that the apoptotic and anti-proliferative effects of capsaicin are enhanced by treatment with lycopene. Several studies have found that capsaicin alone, can up-regulate the generation of ROS and induce apoptosis. We demonstrate that a combination of capsaicin and lycopene induce apoptosis through alterations in the Bax:Bcl-xl ratio with activation of the caspase- 3 cascade in androgen sensitive cell lines, and not the androgen-insensitive cell lines figure 5. It is likely that these effects are downstream of ROS generation and mitochondrial destabilization, which have been previously reported in studies using capsaicin and

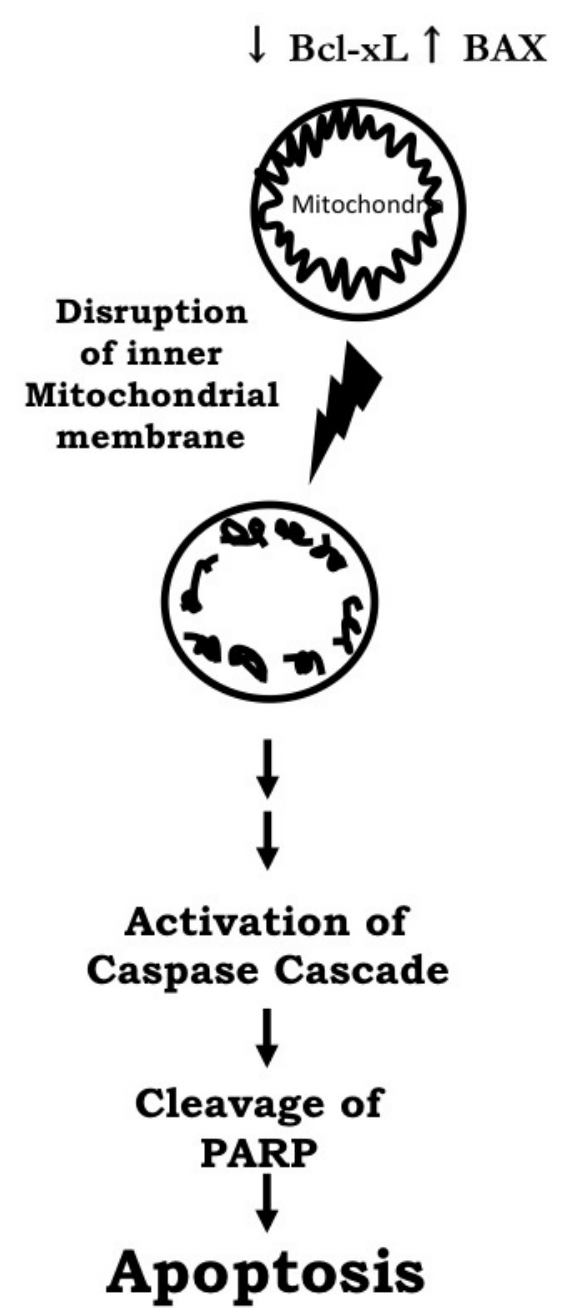

Figure 5. Proposed mechanism for the induction of apoptosis by capsaicin and lycopene in androgen-sensitive cells.

lycopene independently in vitro $[8,16]$.

The dose of capsaicin and lycopene used in our studies were selected based on dose-standardization studies, and previously reported studies $[13,14]$. These concentrations do not reflect the physiological concentration of capsaicin, a major caveat of our study. There is a lack of data detailing the physiological serum concentration of capsaicin and amount of capsaicin in the prostate tissue; however, we are currently investigating whether these concentrations are physiologically relevant using pre-clinical models. Based on our in vitro findings, the effect of capsaicin should be examined in androgen-sensitive xenograft / transgenic model. Previous studies have found that capsaicin alone can reduce the growth of androgen-resistant, PC-3, tumors. Replicating these findings using an androgensensitive model (i.e. LNCaP) with the administration of a combination of capsaicin and lycopene will provide a better understanding of this potential novel therapeutic strategy 


\section{against AR-dependent prostate cancer.}

\section{Conclusions}

In summary, combination studies using dietary agents are promising new approaches to developing effective chemoprevention strategies. Decoding the exact mechanism of action of each agent alone and in combination is the key to a better understanding of the effect of micronutrients on prostate cancer. In our study, we have described for the first time, the chemopreventive interaction of capsaicin and lycopene, two promising dietary agents. Through understanding relationships of these dietary agents, we can postulate the anti-cancer effects of existing widely consumed supplements and aid in the development of supplements that can prevent or even delay the progression of prostate cancer.

\section{Competing interests}

The authors declare that they have no competing interests.

Acknowledgments

We acknowledge the funding support in part to Venkateswaran by $\mathrm{CIHR}$.

\section{Publication history}

Editor: Guan Chen, Medical College of Wisconsin, USA.

EIC: G.J. Peters, VU University Medical Center, Netherlands.

Received: 31-July-2012 Revised: 22-Aug-2012

Accepted: 11-Sep-2012 Published: 09-Nov-2012

\section{References}

1. Canadian Cancer Society's Steering Committee: Canadian Cancer Statistics. Toronto: Canadian Cancer Society, 2010.

2. Bishop FL, Rea A, Lewith $H$, Chan YK, Saville J, Prescott P, von Elm E, Lewith GT: Complementary medicine use by men with prostate cancer: a systematic review of prevalence studies. Prostate Cancer Prostatic Dis 2011, 14:1-13. | Article | PubMed

3. Venkateswaran V, Klotz LH: Diet and prostate cancer: mechanisms of action and implications for chemoprevention. Nat Rev Urol 2010, 7:442-453. | Article | PubMed

4. Venier NA, Klotz LH. Venkateswaran V: Dietary Agents for Prostate Cancer Chemoprevention: An Overview. Current Cancer Therapy Reviews 2010, 6:308-316. | Article

5. van Breemen RB, Pajkovic N: Multitargeted therapy of cancer by lycopene. Cancer Lett 2008, 269:339-351. I Article I PubMed Abstract | PubMed Full Text

6. Giovannucci E: Tomato products, lycopene, and prostate cancer: a review of the epidemiological literature. J Nutr 2005, 135:2030S-2031S. | Article | PubMed

7. Ablin RJ: Lycopene: a word of caution. Am J Health Syst Pharm 2005, 62. | Article | PubMed

8. Hantz HL, Young LF, Martin KR: Physiologically attainable concentrations of lycopene induce mitochondrial apoptosis in LNCaP human prostate cancer cells. Exp Biol Med (Maywood) 2005, 230:171-179. I Article I PubMed

9. Venkateswaran V, Klotz LH, Ramani M, Sugar LM, Jacob LE, Nam RK, Fleshner NE: A combination of micronutrients is beneficial in reducing the incidence of prostate cancer and increasing survival in the Lady transgenic model. Cancer Prev Res (Phila) 2009, 2:473483. I Article I PubMed

10. Tang Y, Parmakhtiar B, Simoneau AR, Xie J, Fruehauf J, Lilly M, Zi
X: Lycopene enhances docetaxel's effect in castration-resistant prostate cancer associated with insulin-like growth factor I receptor levels. Neoplasia 2011, 13:108-119. | Pdf | PubMed Abstract | PubMed Full Text

11. Diaz-Laviada I: Effect of capsaicin on prostate cancer cells. Future Oncol 2010, 6:1545-1550. | Article | PubMed

12. Sanchez AM, Sanchez MG, Malagarie-Cazenave S, Olea N, DiazLaviada I: Induction of apoptosis in prostate tumor PC-3 cells and inhibition of xenograft prostate tumor growth by the vanilloid capsaicin. Apoptosis 2006, 11:89-99. | Article I PubMed

13. Mori A, Lehmann S, O’Kelly J, Kumagai T, Desmond JC, Pervan M, McBride WH, Kizaki M, Koeffler HP: Capsaicin, a component of red peppers, inhibits the growth of androgen-independent, p53 mutant prostate cancer cells. Cancer Res 2006, 66:3222-3229. | Article | PubMed

14. Sanchez AM, Malagarie-Cazenave S, Olea N, Vara D, Chiloeches A, Diaz-Laviada I: Apoptosis induced by capsaicin in prostate PC-3 cells involves ceramide accumulation, neutral sphingomyelinase, and JNK activation. Apoptosis 2007, 12:2013-2024. | Article | PubMed

15. Kim S, Moon A: Capsaicin-induced apoptosis of H-ras-transformed human breast epithelial cells is Rac-dependent via ROS generation. Arch Pharm Res 2004, 27:845-849. | Article | PubMed

16. Zhang R, Humphreys I, Sahu RP, Shi Y, Srivastava SK: In vitro and in vivo induction of apoptosis by capsaicin in pancreatic cancer cells is mediated through ROS generation and mitochondrial death pathway. Apoptosis 2008, 13:1465-1478. I Article I PubMed

17. Jankovic B, Loblaw DA, Nam R: Capsaicin may slow PSA doubling time: case report and literature review. Can Urol Assoc J 2010, 4:E9E11. | Pdf | PubMed Abstract | PubMed Full Text

18. Ivanov NI, Cowell SP, Brown P, Rennie PS, Guns ES, Cox ME: Lycopene differentially induces quiescence and apoptosis in androgenresponsive and -independent prostate cancer cell lines. Clin Nutr 2007, 26:252-263. | Article I PubMed

19. Geng H, Rademacher BL, Pittsenbarger J, Huang CY, Harvey CT, Lafortune MC, Myrthue A, Garzotto M, Nelson PS, Beer TM, Qian DZ: ID1 enhances docetaxel cytotoxicity in prostate cancer cells through inhibition of p21. Cancer Res 2010, 70:3239-3248. | Article | PubMed Abstract | PubMed Full Text

20. Suzuki H, Ueda T, Ichikawa T, Ito H: Androgen receptor involvement in the progression of prostate cancer. Endocr Relat Cancer 2003, 10:209-216. | Article | PubMed

21. Kramer BS, Hagerty KL, Justman S, Somerfield MR, Albertsen PC, Blot WJ, Ballentine Carter H, Costantino JP, Epstein JI, Godley PA, Harris RP, Wilt TJ, Wittes J, Zon R, Schellhammer P: Use of 5-alpha-reductase inhibitors for prostate cancer chemoprevention: American Society of Clinical Oncology/American Urological Association 2008 Clinical Practice Guideline. J Clin Oncol 2009, 27:1502-1516. | Article | PubMed Abstract I PubMed Full Text

22. Lee C, Sutkowski DM, Sensibar JA, Zelner D, Kim I, Amsel I, Shaw N, Prins GS, Kozlowski JM: Regulation of proliferation and production of prostate-specific antigen in androgen-sensitive prostatic cancer cells, LNCaP, by dihydrotestosterone. Endocrinology 1995, 136:796803. I Article I PubMed

23. Khan N, Adhami VM, Mukhtar H: Apoptosis by dietary agents for prevention and treatment of prostate cancer. Endocr Relat Cancer 2010, 17:R39-52. | Article | PubMed Abstract | PubMed Full Text

\section{Citation:}

Venier NA, Colquhoun AJ, Fleshner NE, Klotz LH and Venkateswaran V: Lycopene enhances the antiproliferative and pro-apoptotic effects of capsaicin in prostate cancer in vitro. journal of Cancer Therapeutics and Research 2012, 1:30.

http://dx.doi.org/10.7243/2049-7962-1-30 